\title{
Fuzzy inference system-Latin hypercube simulation: An integrated hybrid model for OHS risks management
}

\author{
Ehsan Haqiqat $^{a^{*}}$, Yahia Zare Mehrjerdi ${ }^{\text {a }}$ and Ali Zare Bidaki ${ }^{\text {b }}$
}

${ }^{a}$ Department of Industrial Engineering -Yazd University. Iran

${ }^{b}$ Department of construction Management - University Technology Malaysia

C H R O N I C L E

Article history:

Received: July 202018

Received in revised format: No-

vember 12018

Accepted: November 212018

Available online:

November 212018

Keywords:

Occupational Health and Safety

Healthcare System

Construction Projects

Risk Evaluation

Risk Management

Sensitivity analysis

\section{A B S T R A C T}

Risk management in construction industry in several cases is not only incomplete regarding the unification of Occupational Health and Safety (OHS) hazards, but it is also incomplete in not having a systematic and innovative method to assess the impacts of these risks on the objectives of a project. An integrated hybrid Fuzzy Inference System-Latin Hypercube Simulation for the evaluation of OHS risks in construction projects is presented in this paper. Prioritization of safety risks systematically without human interference with fuzzy inference system gives the appropriate response to the identified risks. An advanced Monte Carlo simulation is also used for the evaluation of quantitative objectives of a project. This approach allows us to get away from discrimination and simulate the risks with high impacts but with low probabilities. In order to measure the relationship between the occurrences of each of the risks impacts on project objectives, the sensitivity analysis based on Pearson correlation coefficient is used to determine the usefulness of the proposed integrated hybrid method.

C) 2019 by the authors; licensee Growing Science, Canada.

\section{Introduction}

The industrial safety and occupational health risks are the most important types of risks. In other words, in this kind of risk, probability and severity of an incident or injury lead to risk occurrence. The occurrence of such risks in construction projects inflicts high costs of the project and causes delay in the project. Systematic analysis of safety risks and the impacts of them on the objectives of a project (time and cost) can lead to better planning and scheduling. Planning, identification, quantitative and qualitative analysis, responding, controlling and inspecting on risk along the project are the key steps of risk administration. The main challenge of risk management is the accurate estimation of probabilities or uncertainties of the future. Reviewing the literature illustrates that there is still significant inefficiency in systematic assessment of occupational health and safety risks in projects. Relevant studies in this scope are mainly conceptual frameworks that consist of a general assessment of risk unreliability in projects and specifying strategies in order to reduce the risk level. This article offers a hybrid fuzzy inference system-latin hypercube simulation approach to the evaluation of job-related health and safety risks in construction projects. The aim of this article is to design a hybrid fuzzy inference system and simulation in order to support project managers in various situations of decision making based on risk management. The proposed hybrid model calculates risks ranking and their impacts in a systematic

* Corresponding author.

E-mail address: ehsan.haqiqat@gmail.com (E. Haqiqat) 
environment with fuzzy inference system. Then, the project time and cost plans are simulated with an advanced Monte Carlo (Latin Hyper Cube simulation) in three phases (before identification of risks, after identification of risks and finally, after doing corrective actions).

In this research, triangular distribution is used for project activities. The new proposed model aggregates areas of fuzzy inference system, Latin hyper cube simulation and projects risk management. Designing a fuzzy inference system to rank risks in order to perform corrective action and to have a responding plan with systematic method and without personal viewpoint interference are other innovations of the research. In this article, enhanced Mont Carlo method (Latin hyper cube) will also be used for the assessment of safety risk effects on project objectives. This new method lets us check and simulate risks with high rate of occurrence, but with low probability (for example, the occurrence of explosion in construction projects has low probability but happening of this risk has a great impact on the project) which in the classic Monte Carlo simulation the evaluation of these kind of risks (low probability-high impact) is not possible.

\section{Literature Review}

Uncertainty can be explained as the occurrence that its likelihood of the event sets between 0 and 1(Hagigi \& Sivakumar, 2009). As mentioned in (PMI, 2008) risk appears because of uncertainty. Beta or triangle distributions are regularly used for modeling uncertainty (Kendrick, 2015). Uncertainty can be delineated by probability distributions. Project Risk Management covers the way of leading danger administration programming, identification, analysis, response planning, monitoring and controlling on a project plan (PMI, 2008). Liu and Guo (2009) explained that the key step and the basis of risk management process is the risk identification. OHSAS 18001 (Lafuente \& Abad, 2018) has stressed that by lowering risk probability or its severity, we can reduce the risks. Risk is clarified as the impact of uncertainty on the achievement of targets. It is also defined as an innate in the occupations of men and all companies (Badri et al., 2012). As mentioned in OHSAS 18001 Risk is a combination of the probability and the consequences of the occurrence of a specified dangerous event (Pheng \& Kwang, 2005). "OHS Risk" is the significance of a hazard, in terms of the probability, and severity of an injury or illness occurring as a result of the hazard. In chapter 3 of the construction extension to the (PMI, 2008), PMI ${ }^{\circledR}$ gave an overview of the project safety management processes. This procedure includes "all activities of the project sponsor/owner and the performing organization which determine safety policies, objectives, and, responsibilities so the project is planned and executed in a manner that prevents accidents, which cause, or have the potential to cause, personal injury, fatalities, or property damage". Danger is a mixture of likelihood and side effects of the happening of a particular risky occurrence (OHSAS 18001). "OHS Risk" is the importance of a threat, depending on likelihood, and harshness of a damage or sickness resulting because of the threat. In part 3 of the construction development to the

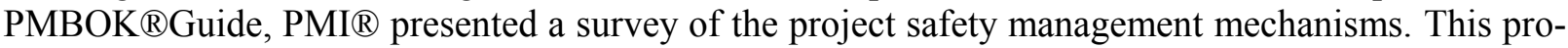
cedure involves "the entire actions of the project advocate/holder and the operating institution which resolve safety directions, aims, and duties so that the project is arranged and performed in a way that avoids mishaps which impel or have the possibility to impel individual damage, deaths, or wealth damage". The term of safety management has been defined in PMI ${ }^{\circledR}$ by both health management and safety management. All aspects of project management interact with project safety management (Construction Extension to the PMBOK ${ }^{\circledR}$ Guide). To manage and identify OHS risk linked with a plan, an institution needs engagement and attendance of each person who has a role in the project such as specialists in risk analysis, stakeholders, end users, experts, customers, risk management team, project team members, and the project manager(Hare, Cameron, \& Roy Duff, 2006). Qualitative evaluation continues to be important in programming OHS risk (like compiling information, designing strategies, and specialist idea). Qualitative evaluation is usually enhanced by a quantitative study to a likely amount. Pursuing danger evaluation, the process is finished by selecting and unifying a danger management action plan with the project administration course as a sign to assess the efficiency of the method of PMBOK ${ }^{\circledR}$ Guide, (PMI, 2008). In project administration, based on Aubert and Bernard (2004) risk is 
explained as the mixture of the feasibility of happening and the influence of a happening. The comparison as it was recommended by (Aubert \& Bernard, 2004) to compute and prioritize risks at the end of the assessment stage is:

Risk (i) =Feasibility Unwanted Happening (i) $\times$ Effect Unwanted Happening (i)

Moreover, the designed system not only contains deploying integrated process of risk management, but it is also capable of getting professional's comment feedback. As mentioned in OHSAS 18001-1991 safety is defined as the rate of escape from hazards (Monarca, Cecchini, Colantoni, Gubiani, \& Vello, 2008). Each person or organization according to his knowledge of hazards and capabilities can escape from danger. OHSAS 18001 Standard accentuates that to decrease probability or severity of risks occurrences, risks effects can be reduced. Occupational and health safety risk is a type of risk which is so important because of its relation to human health. In other words, the probability and severity of an incident or injury lead to risk occurrence. In order to manage and identify project safety risk, an organization needs the cooperation of all project stakeholders. These stakeholders comprise of risk analysis experts, end users, project management teams and project managers (Hare et al., 2006). In terms of historical view, the construction industry has the highest rate of fatal or nonfatal injuries and all around the world remains one of the most dangerous occupations till now. The published information from the American work force in 2007 reveals that in the USA construction industry, the rate of death and incidence are triple the other industries. With respect to the status of national institute of Portugal from 2000 up to 2006, approximately half of fatal accidents in this country have been happening in the construction industry (INE, 2008). Obviously, consequences of construction incidence have high expense in this industry (Lee et al., 2006). The cost resulting from injuries and damages depends on the occupation and the part of the body that is injured and it would be different. For example, (Leigh \& Miller, 1997) reported that construction workers and carpenters are the two jobs that face with a high cost in the area of occupational injuries and damages. (Dement, 1999) reported that construction workers and carpenters have higher medical costs than the average of other occupations. Researches illustrate that more than 30000 claims for compensation belonged to the members of construction workers in North Carolina for the period of 1986-1994. (Waehrer et al., 2007) report that construction workers have the highest fatality record (299 cases), and as a result the highest average of mortality cost (1200 million \$) annually. (Lipscomb et al., 2006) demonstrate that more than 20000 claims for compensation have been opened by a construction worker in Oregon between 1990 up to 1997. A report in year 2003 , (Lipscomb et al., 2003) revealed that the highest claim expenses of carpenters referred to residential construction between 1995 to 2000 which led to $14 \%$ of claim results in $83 \%$ of the expenses passing 10 Million dollars. (Harms-Ringdahl, 2003) by citing a research in 1997 about nine European countries estimates that economical cost of occupational injuries in country encompass $2.5 \%$ to $6 \%$ of gross domestic product of the country.

The main step in the process of risk management is risk identification (Liu \& Guo, 2009). With an overall view, the process of risk management consists of three stages as follows: identification, analysis and risk response respectively (Badri et al., 2012). This article not only considers the process of risk management and quantitative analysis with the fuzzy inference system, but it also considers using promoted Mont Carlo method to simulate the project objectives. According to the (Siegel et al., 1995), the fuzzy logic has helped to promote the technology of expert systems by simulation techniques and the demonstration of exhibiting models. The fuzzy logic depends on its capability to address important and imprecise information which is a crucial tool for decision making. Studies in recent years reveal that utilization of fuzzy logic in scope of risk management in construction projects is being addressed dramatically by researchers in this field (Islam et al., 2017). (Deshmukh \& Romine, 1998) offered a decision making model by using the theory of fuzzy sets used for the evaluation of risk management. The predicted techniques in the book of Guide to the Project Management Body of Knowledge were well described explained and have been updated. In this book, the way of techniques and tolls evaluation as well as the level of their access to goals is not specified. Lots of researchers have studied for evaluation and classification of risks (PMI, 2008). (Jannadi \& Almishari, 2003)studied about the risks evaluation 
in construction project activities. These authors define risk as a measurement of contingency and severity. They offered a model to determine level of risks by considering all risks related to an activity. They stated that the determination of high risk activities by means of this method leads to a more efficient performance of safety actions for the contractors of construction projects. (Baradan \& Usmen, 2006) developed a method for career analysis due to mortality and injuries in construction project. They use effect-probability method to determine their risk level and classification. (Hallowell, 2008) developed a method to assess safety risks and to respond to them in the reliable process of construction. They also identified the risks related to construction activities in a case study and then, necessary safety measures provided in confrontation of risks, based on the Newton's third law (similar and reversed reactions comes from every action). After that, according to the classic method, level of probability and severity of risks were calculated and also, amount of probability and severity reduction of risks has been measured in the implementation of safety measures. The deficiency of most of these studies is that their proposed models are not systematic. It means that because the OHS risks are related to human beings' health, a little mistake can cause major problems. (Gürcanli \& Müngen, 2009) revealed a method to evaluate risks in construction project by using safety analysis form according to if-then fuzzy rules. Using fuzzy analysis method leads to the consideration of uncertainties in the data and utilization of historical data of safety risks which result in better subjective judgment of experts for quantitative analysis. Therefore, creation of fuzzy systems can ease the utilization of fuzzy analysis for the user and eliminate the human errors.

Rozenfeld et al. (2010) presented a risk assessment model in a construction environment. Their studies demonstrate that the safety analysis approach in a production environment has been effective, but because of workers' movement from one environment to another and the involvement of their jobs in other teams, there is a need to develop a model in civil projects. They presented a structured approach for safety risk analysis in a construction project to perform safety measures for risk by specifying the fluctuation of risks level. They proposed a method with the title of 'Construction Job Safety Analysis' for the identification of important risks. They considered probability and severity of risks as definitive but with the expression of uncertainty and risk exposure in the form of fuzzy sets, project experts will be able to simulate safety risks impacts on project objectives by designing a fuzzy inference system without human intervention.

Benjaoran and Bhokha (2010) proposed an integrated system for construction safety management in the process of designing, planning and controlling. Their proposed model is a conceptual model that it is not possible to measure and assess it. Wu et al. (2010) worked on the development of a systematic approach to respond to safety risks in construction projects. This approach is designed for rapid and in time responding to safety risks. Pinto et al. (2011) reviewed the literature of researches on safety risks in construction projects. They have perfectly evaluated safety risks studies of the other researchers. Badri et al. (2012) presented an analytic approach based on risk factors to unify job-related health and safety with project risk management. They use the analytic hierarchy process (AHP) for assessment and prioritization of industrial and occupational health safety risks. They also considered the process of risk management as an integrated process. This approach is one of the newest methods of safety risk assessment. Aminbakhsh et al. (2013) also proposed safety risk assessment using analytic hierarchy process (AHP) along programming and planning money (budgeting) for the construction project plans. Their approach is just applicable for analysis ranking. Zare Mehrjerdi and Haqiqat (2015) introduced a conceptual model development based upon the Latin Hypercube Sampling for integrating OHS into project risk evaluation. The survey of literature reviews indicates that project administration in construction industry in several cases is not only incomplete regarding the unification of Occupational Health and Safety (OHS) dangers, but it is also incomplete in not having a systematic and innovative method to assess the impacts of these risks on the objectives of a project. In this article, the proposed hybrid model considers the integration of identification, analysis and OHS risks responses and is compatible with an expert viewpoint. 


\section{Materials and methods}

\subsection{Latin Hypercube Sampling Theory}

Latin Hypercube Sampling (LHS) is a numerical method to derive a model of reasonable collection of criteria principles from a multi-faceted dispersion. The modeling method is usually performed in ambivalence measurement which was first explained by (McKay et al., 1979) and it was expanded more by (Iman et al., 1981). When we investigate the operation of $\mathrm{N}$ variables, the extent of every variable is broken down into $M$ the same possible breaches. Next, $M$ sample spots are located to please the Latin Hypercube necessities; It should be mentioned that this stage makes the total of $\mathrm{M}$ divisions to be the same for every variable. Furthermore, it should be cited that this modeling program needs no more samples for further variables and autonomy is one the major utilities of this modeling program. The other advantage is that incidental models are made one at every time by having this point in mind that which models were made up to now. The utmost number of mixtures for a Latin Hypercube of $\mathrm{M}$ divisions and $\mathrm{N}$ variables (dimensions) are determined with the below formula:

$$
\left(\prod_{n=0}^{M-1}(M-n)\right)^{\mathrm{N}-1}=(\mathrm{M} !)^{\mathrm{N}-1}
$$

\subsection{Latin Hypercube sampling VS Monte Carlo Simulation}

Statisticians have expanded diverse ways to model from dispersions. These ways would lead to similar results if we could do boundless number of iterations in our duplication. However, as we apply limited number iterations, modeling ways do not create similar outcomes. A modeling way is regarded more efficient than the other provided that it borders a dispersion with fewer iterations. There are two wellknown modeling ways as

Monte Carlo Simulation and Latin Hypercube Sampling.

Sampling is the way through which principles are established haphazardly from the selected dispersion. As cited in (Kautt \& Wieland, 2001) Monte Carlo, simulation chooses models from the complete amount of dispersion in every draw which is an entirely accidental modeling strategy. Most seen measurements are closer to the mean and make clustering. The tails (the zones of high ambiguity) are mainly marginalized in the modeling while in Latin Hypercube, simulation of samples from all parts of the distribution, lessening clustering. It means that versus the Monte Carlo, Latin Hypercube is not entirely random and it is a stratified sampling method. Latin Hypercube divides a distribution into similar intervals of possibility and accidentally draws from each interval and insures that all portions of the distribution are sampled, including the tails (areas of high uncertainty). Therefore, Latin Hypercube modeling is further efficient than Monte Carlo sampling because it requires less iteration. The essential issue to Latin Hypercube modeling is the classification of the input likelihood dispersions. This classification breaks the increasing curve into equal intervals on the increasing likelihood measurement ( 0 to 1.0). Next, the model is accidentally achieved from the classification of the input dispersion. Modeling is compelled to show the values in every interruption and in this manner is compelled to make the input likelihood dispersion again. As a further impressive modeling approach, Latin Hypercube proposes considerable advantages depending on the expanded modeling usefulness and quicker run-times (due to not many iterations). These advantages are chiefly evident in a personal computer based duplication situation like Pert Master software. While performing a duplication, it is crucial that all aspects of the input dispersion get modeled, particularly the little likelihood (great ambiguity) fields. Provided that this is not the case, ambiguity will appear smaller than really is. Latin Hypercube contributes to the examination of the instances where few likelihood results are shown in input likelihood dispersions. This belonging of Latin Hypercube modeling leads to better and more accurate measurement of OHS dangers. Classification of the input likelihood dispersions authorizes the measurement of situations where likelihood outcomes are few. 

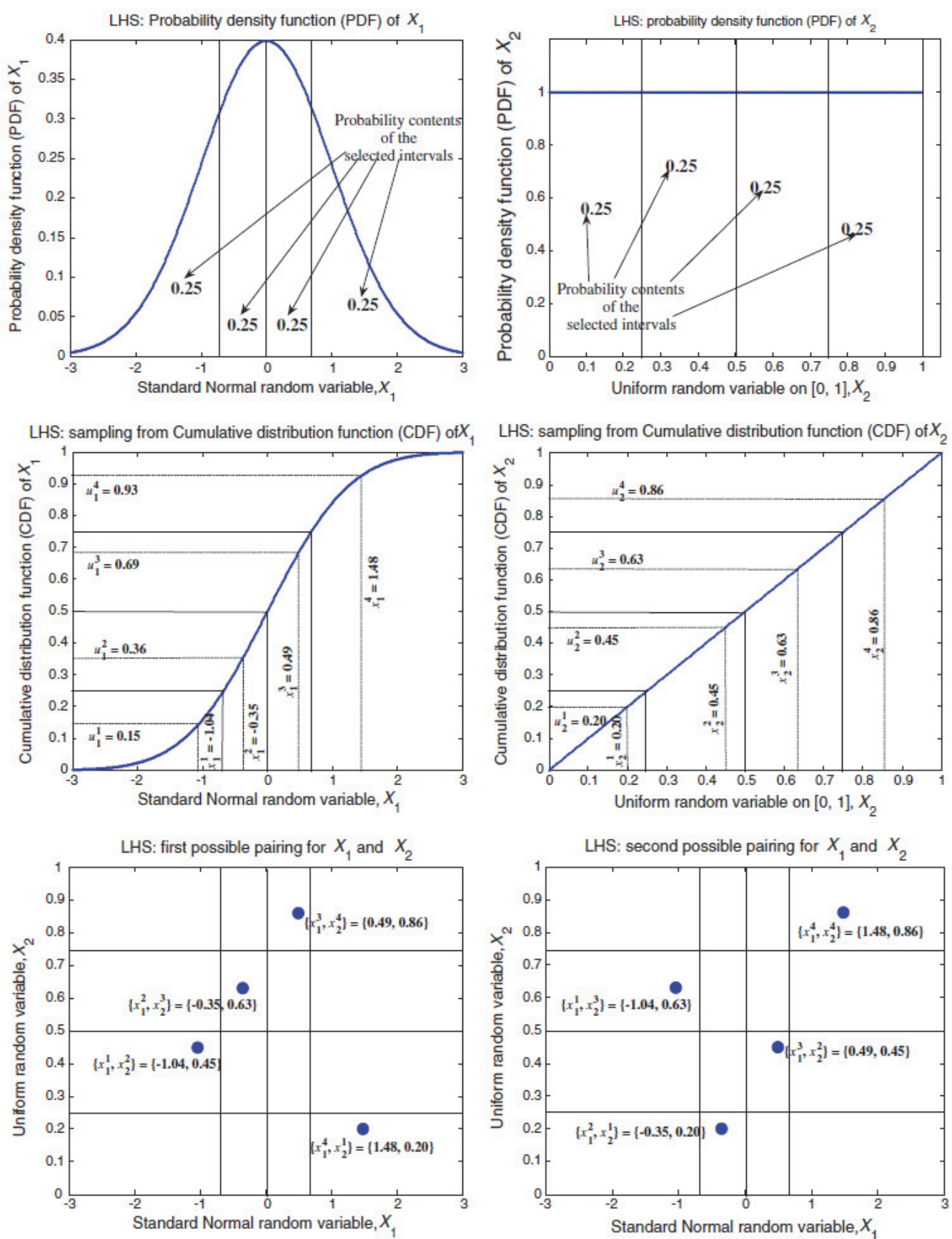

Fig. 1. samples of LHS for the creation of a model size of NT=4 from two rvs $\left\{X_{1}, X_{2}\right\}$ with $X_{1}$ standard (first) and $X 2$ consistent on ( 0 , 1 ) (second). Leading pdfs (bulky tight lines): third and fourth pdfs (bulky tight lines) and equivalent separated breaks of similar likelihood (slender tight lines); fifth and sixth two likely Latin hypercube examples of size NT=4 rising from two dissimilar likely accidental pairings (dots).

In case of mathematical modeling, a square grid comprises of model location of a Latin square provided that the model remains in every row and column. Method of Latin Hyper Cube sampling has been defined for drawing $\mathrm{N}_{T}$ sample of (n) Independent variable $\left[X_{j}: j=1,2, \ldots, n\right]$ that each element has distribution of $[q j(0): j=1,2, \ldots, n](Z i o, 2013)$. The range of each variable was divided into the discrete interval in number of $\mathrm{N}_{\mathrm{T}}$ unit. Afterward, according to each variable probability distribution [qj(0) : $\mathrm{j}=1,2, \ldots, \mathrm{n}]$, a quantity of variable is selected for each distance randomly. These $\mathrm{NT}_{\mathrm{T}}$ organized couples are mixed accidentally without being replaced with NT values $X_{3}^{k} \mathrm{k}=1,2, \ldots, \mathrm{N}_{\mathrm{T}}$ of $\mathrm{X}_{3}$ to form the $\mathrm{N}_{\mathrm{T}}$ ordered triples: 
$X_{k}=\left\{\mathrm{X}_{1}^{\mathrm{k}} \cdot \mathrm{X}_{2}^{\mathrm{k}}, \mathrm{X}_{3}^{\mathrm{k}}\right\}, \mathrm{k}=1,2, \ldots, \mathrm{N}_{\mathrm{T}}$.

The process is done again for the entire $\mathrm{n}$ variables till a group of NT n-tuples is achieved. Fig. 1 shows samples of LHS for the creation of a model.

\section{The proposed hybrid method}

This study suggests a hybrid model for integrating occupational health and safety into project risk evaluation based upon Fuzzy Inference System (FIS) and Latin Hypercube Sampling (LHS). The entrance of the system comprises of time schedule, activities, cost and a recognized risk list as Figure 2 reveals. In this research, the triangular distribution is chosen for risks of activities by expert's viewpoint. The most used distribution for uncertainty in the literature of project management was Beta and triangular distribution (Kendrick, 2015). Rectangular distribution can be shown by three estimations of optimistically, probable and pessimistic values. After safety risks are prioritized based on designing a fuzzy inference system, consolidate time schedule of risks and activities is made. After responding plan to the risks, objectives of the project will again be simulated. As the Figure 2 reveals, simulation project objectives for three plans 1) before identification of risks, 2) after identification of risks (before responding to risks) and 3) after responding to risks by the Latin Hyper Cube method is done. Due to the comparison and assessment of simulation result, which were obtained from schedule, three gained schedules will be summarized in a unite style to a specified level of delay or ahead of plans in comparison with each other. Next, system results will be validated in a meeting with project manager and safety manager. If final results accept by the experts, system process is finished successfully otherwise the process of system is repeated from prioritization level with fuzzy inference system.

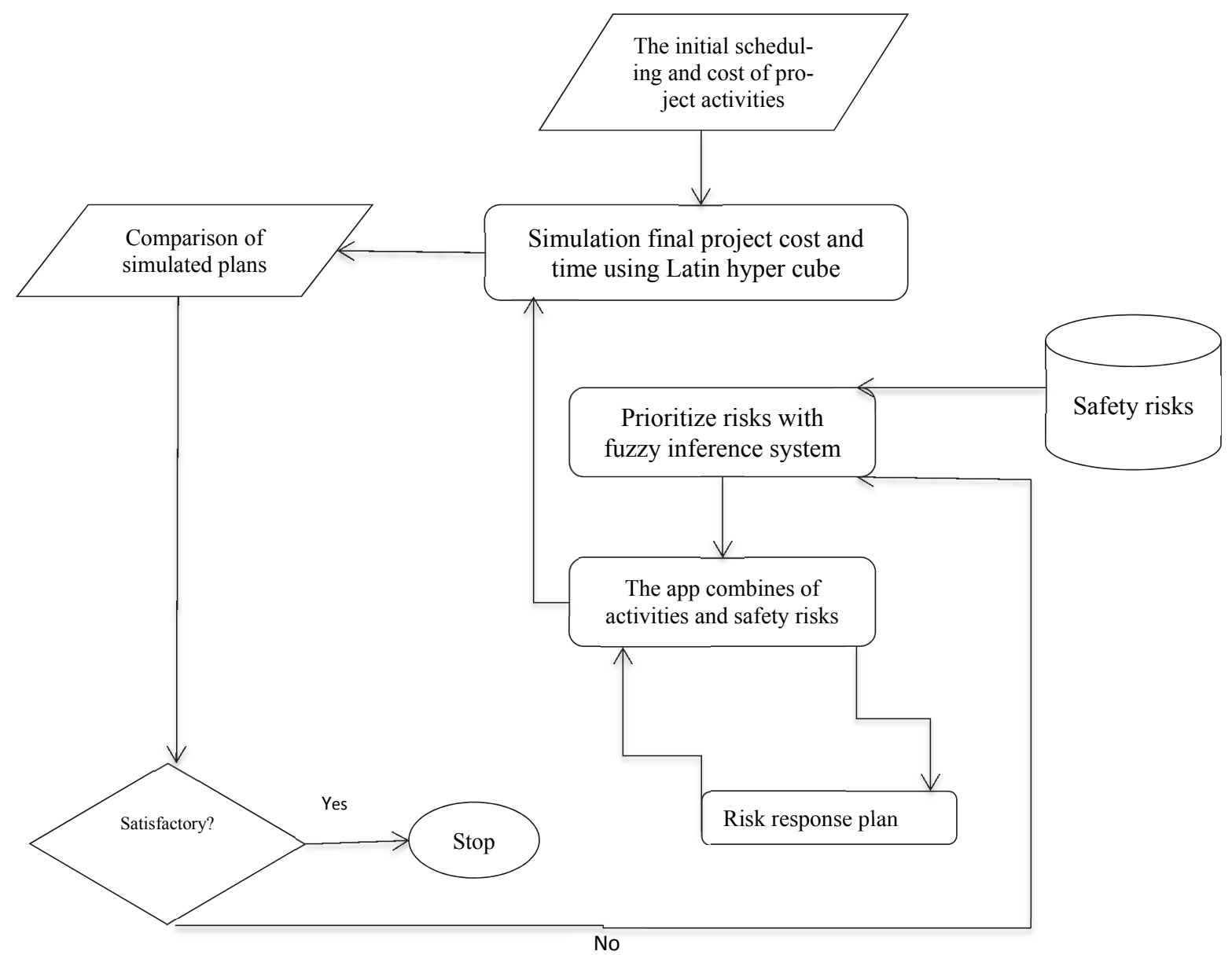

Fig. 2. Suggested hybrid model for study the effects of safety risks on project objectives 
In this Integrated Hybrid model, Risk management process is broken into three stages of(1) risk recognition; (2) risk/danger measurement and (3) alleviation activities. This model allows the decision makers such as project managers to compare the impacts of mitigation actions before and after mitigations.

\section{Results}

\subsection{Case study}

The case study of this article is about construction and installation of special glasses on the complex geometric structure of a project. This project is located in Mashhad city in Iran. This project is assessed in terms of health and safety occupation risks. Project safety risks were identified in a meeting by project safety managers' attendance and the risks are also identified according to the risks database that has been provided as an example in Table 1 . To identify project safety risks, in a meeting by the author of the research, the project manager, safety expert and project controller expert, and by brainstorming and providing safety risks database and reviewing of literature, safety risks related to the installation of glasses on the geometric structure were identified (Fig. 4).

Applying Pertmaster Software for risk analysis lets a project manager to evaluate a Critical Path Method (CPM) project plan by applying likelihood distributions of the task durations. To perform risk analysis in Pertmaster, primarily it is needed to run a CPM plan, which comprises of incoming tasks and indicators and adding logic to define task connections. Then, the risk duration distribution for every task is arranged and this signifies that every task is allotted minimum, most likely, and maximum durations. The task connections and OHS risks are added to the related tasks. In Pertmaster software we use risk register to:

- Define risks (threat and opportunity) including risk owner, causes, effects, status, probability and cost, time and custom impacts and fields.

- Track any detailed actions used to mitigate the probability and impact of risks using a mitigation plan.

- Map risks to tasks and Work Breakdown Structures (WBS) items.

- Define the impact a risk has on each task or the WBS item it is mapped to.

- Quantify the schedule, cost, performance and the environment impact caused by the risks on the project.

- Compare Pre-Mitigation and Post-Mitigation scenarios.

In the following subsections of the paper, in the structure of a case study we describe and analyze in more detail the 3 phases of the proposed approach used to manage OHS risks.

In our research, we used triangle distributions for risk analysis according to the expert's view. The most utilizable likelihood distributions described in the project management literature for modeling uncertainty are Beta and Triangle (Tong et al., 2018). Triangle distributions can be represented by three approximations of optimistic, pessimistic, and most likely values. Van (Van Dorp \& Duffey, 1999) stated that the choice of Beta or Triangle distribution to model activity duration has a somewhat small effect on simulation results for the total project duration. When a risk plan is built, the mitigation actions are added as new tasks to the built risk plan. After mapping the risks to the tasks in the project, the premitigated and post-mitigated risk plans can be built. Building a risk plan creates a new schedule that contains the cost and schedule impacts. The pre-mitigated model is built using the probabilities and impacts associated with the pre-mitigated mappings while the post-mitigated model is built using the probabilities and impacts associated with the post-mitigated mappings. Table 1 shows the pre-mitigated and post-mitigated plans.

The overall impact of a risk is set to the highest of all impacts. Each risk impact is given a numeric value: Negligible $=0, \mathrm{VL}=1, \mathrm{~L}=2, \mathrm{M}=3, \mathrm{H}=4, \mathrm{VH}=5$. The highest of all the impacts of these is used to determine the overall impact. In this case study, a risk register has 4 impact types and 5 impact values (VL, L, M, H and VH). For instance, if a risk is assessed as follows: Cost impact $=\mathrm{H}$, Schedule impact $=\mathrm{N}$, Performance impact $=\mathrm{N}$, Environmental impact $=\mathrm{N}$, Numerical impact $=4$ then, the overall 
impact is set to $\mathrm{H}$. Depending on the predicted definite preliminary schedule, the project starts at $11 / 08 / 2014$ and finishes on $21 / 05 / 2015$ and it means that the project last 284 days. Furthermore, in the project's definite schedule, expenditures of the project were predicted 93100 units of money.

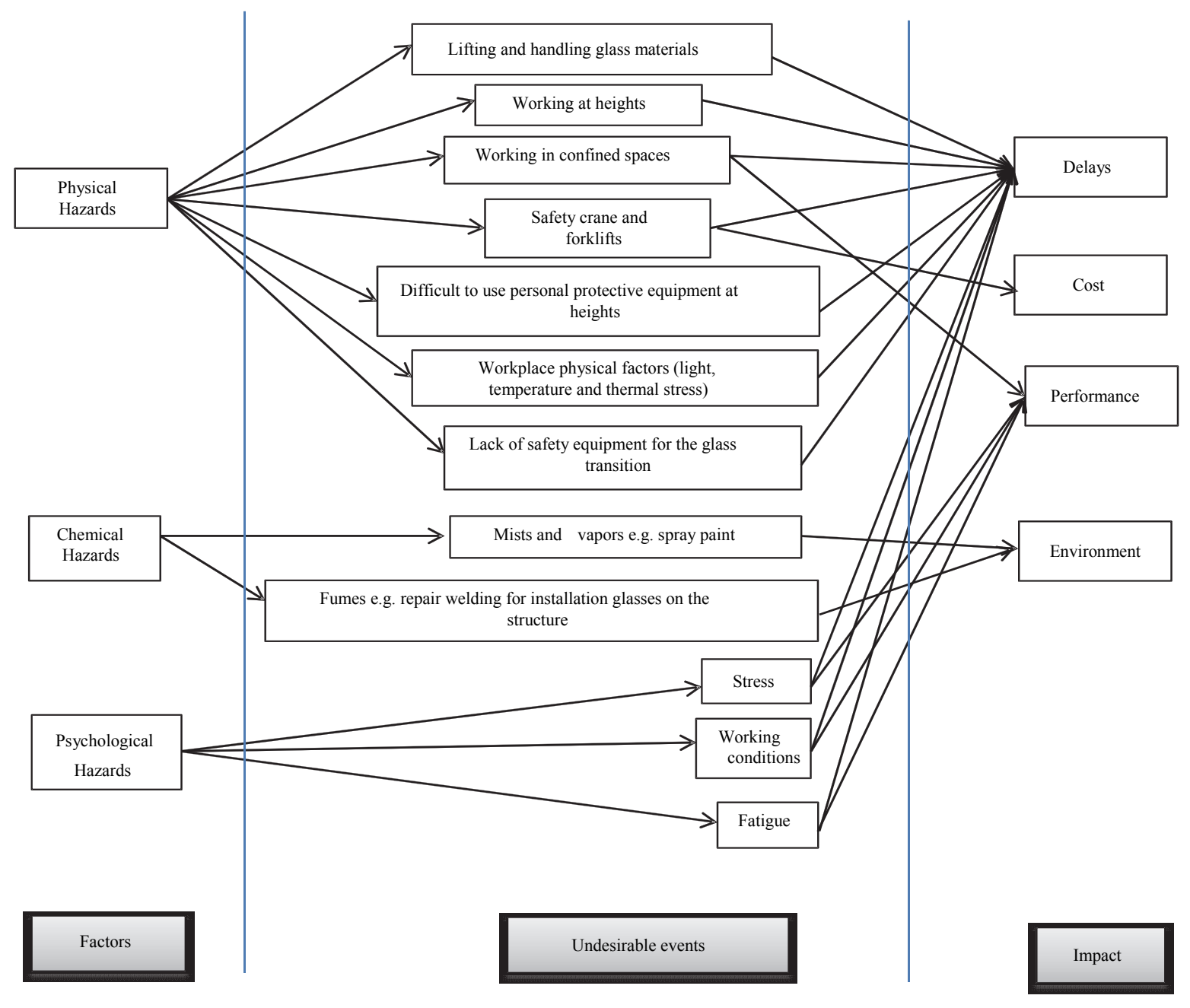

Fig. 4. Case study: links between undesirable events, their risk factors and their impact.

Table 1

Case study: mitigation plan (Pre-mitigation plan, Response, Post-mitigation plan)

\begin{tabular}{|c|c|c|c|c|c|c|c|c|}
\hline \multirow{3}{*}{$\begin{array}{l}\pi \\
\stackrel{\Sigma}{\&}\end{array}$} & \multirow{3}{*}{ Risk/Event } & \multicolumn{3}{|c|}{ Impact Analysis } & \multirow{3}{*}{$\begin{array}{l}\text { Mitigation } \\
\text { Plan }\end{array}$} & \multicolumn{3}{|c|}{ After Mitigative Plan } \\
\hline & & \multirow{2}{*}{ Uncertainty } & \multicolumn{2}{|c|}{ Impact } & & \multirow[t]{2}{*}{ Uncertainty } & \multicolumn{2}{|c|}{ Impact } \\
\hline & & & Time & Cost & & & Time & Cost \\
\hline 1 & Working at heights & $\mathrm{H}$ & $\mathrm{H}$ & $\mathrm{N}$ & Reduce & $\mathrm{L}$ & $\mathrm{L}$ & $\mathrm{N}$ \\
\hline 2 & crane and forklifts Safety & $\mathrm{H}$ & VH & $\mathrm{N}$ & Reduce & M & M & $\mathrm{N}$ \\
\hline 3 & Lifting and handling glass materials & $\mathrm{H}$ & $\mathrm{L}$ & $\mathrm{L}$ & Avoid & $\mathrm{N}$ & $\mathrm{N}$ & $\mathrm{N}$ \\
\hline 4 & Working condition & M & $\mathrm{H}$ & VH & Reduce & $\mathrm{L}$ & $\mathrm{H}$ & $\mathrm{VH}$ \\
\hline 5 & Fatigue & M & $\mathrm{L}$ & $\mathrm{N}$ & Accept & M & $\mathrm{L}$ & $\mathrm{N}$ \\
\hline 6 & Glass transition Lack of safety equipment for the & M & $\mathrm{L}$ & $\mathrm{N}$ & Accept & M & $\mathrm{L}$ & $\mathrm{N}$ \\
\hline 7 & Stress & M & M & $\mathrm{N}$ & Reduce & $\mathrm{L}$ & M & $\mathrm{N}$ \\
\hline 8 & Working in confined spaces & $\mathrm{L}$ & $\mathrm{N}$ & $\mathrm{N}$ & Accept & $\mathrm{L}$ & $\mathrm{N}$ & $\mathrm{N}$ \\
\hline 9 & Mists and vapors e.g. spray paint & $\mathrm{N}$ & $\mathrm{N}$ & $\mathrm{N}$ & Accept & $\mathrm{N}$ & $\mathrm{N}$ & $\mathrm{N}$ \\
\hline 10 & Difficult to use personal protective equipment at heights & $\mathrm{H}$ & $\mathrm{M}$ & $\mathrm{N}$ & Reduce & $\mathrm{L}$ & M & $\mathrm{N}$ \\
\hline 11 & $\begin{array}{l}\text { Workplace physical factors (light } \\
\text { and thermal temperature stress) }\end{array}$ & $\mathrm{H}$ & $\mathrm{N}$ & $\mathrm{N}$ & Reduce & $\mathrm{L}$ & $\mathrm{N}$ & $\mathrm{N}$ \\
\hline 12 & Fumes e.g. repair welding for installation glasses on the structure & $\mathrm{H}$ & $\mathrm{N}$ & $\mathrm{N}$ & Avoid & $\mathrm{N}$ & $\mathrm{N}$ & $\mathrm{N}$ \\
\hline
\end{tabular}




\section{Fuzzy inference system}

Fuzzy systems are the systems that depend on knowledge or rules. The core of the fuzzy system is based on knowledge which is formed by fuzzy if-then rules. A fuzzy if-then law is an if-then explanation that a few of its words have been specified by means of constant participation actions. In fact, the starting point of a fuzzy system is gathering a set of fuzzy if-then rules from expert knowledge or studied knowledge area. The next step is a combination of such rules in a single system. As an expert's opinion, the fuzzy variable system which comprises of uncertainty event, final effect, and risk in five fuzzy sets, very little, little, medium, high and very high are defined in Matlab software. Additionally, system rules are specified by an interview with safety managers of projects. By using designed fuzzy system in Fig. 5, it is possible to rank safety risks in construction projects to do the corrective action (responding plan to risk) in accordance with obtaining priority by fuzzy inference system.

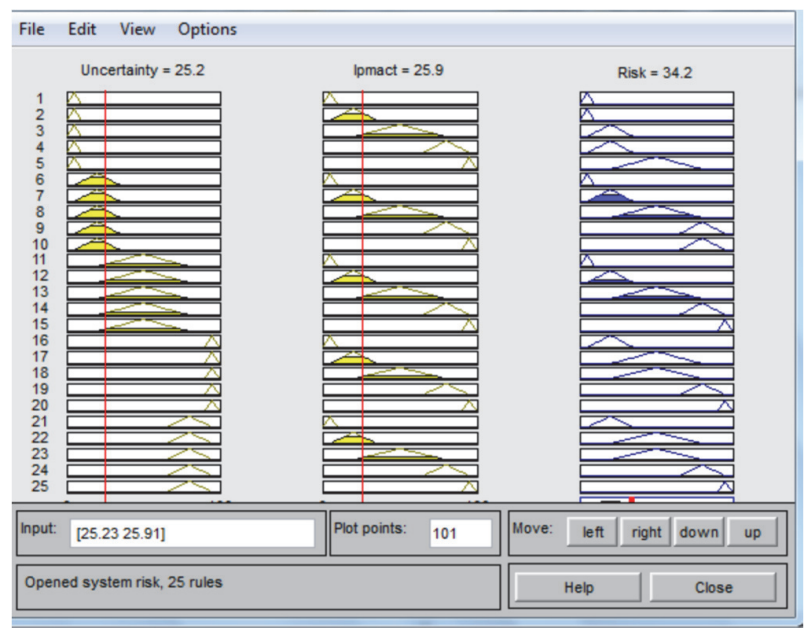

Fig. 5. Fuzzy inference system designed in order to prioritize safety risks

\subsection{Identification, Prioritization and Responding to Safety Risks}

After interviewing the safety manager and determining the unreliability of occurrence and identifying risks, the effects and strategies related to risks (risk ranking) will be obtained according to the priorities that come from the fuzzy inference system result. Table 2 demonstrates considered strategies coping with risks.

Table 2

Final risks ranking

\begin{tabular}{clcc}
\hline Risk Symbol & Risk description & Score & Rank \\
\hline R1 & Working at heights & 95 & 1 \\
R2 & Safety crane and forklifts & 95 & 2 \\
R3 & Lifting and handling glass materials & 80 & 3 \\
R4 & Working condition & 80 & 4 \\
R5 & Fatigue & 80 & 5 \\
R6 & Lack of safety equipment for the glass transition & 50 & 6 \\
R7 & Stress & 50 & 7 \\
R8 & Working in confined spaces & 50 & 8 \\
R9 & Mists and vapors e.g. spray paint & 50 & 9 \\
R10 & Difficult to use personal protective equipment at heights & 20 & 10 \\
R11 & Workplace physical factors (light temperature and thermal stress) & 20 & 11 \\
R12 & Fumes e.g. repair welding for installation glasses on the structure & 20 & 12 \\
\hline
\end{tabular}


Based on Table 1 and according to the fuzzy inference system results, risks with number 2 and 4 have the highest priority to respond and execute safety actions. Risks with number 1, 11, 12 stay at second level and 7,10,3 and 8 are at level three and risks with number 5, 6 and 9 are ranked at level fourth. By using Latin Hyper Cube simulation method in Pert Master software, time and schedule cost of the project are simulated and predicted. Table 2 shows consolidate plan of activities and safety risks after the specification of strategies and the execution of corrective actions.

\section{Discussion}

Comparing the outcomes of simulation by a Latin Hyper Cube method to obtain the end date of the project reveals that if project managers do not consider safety risk and do not perform corrective action by a probability of 80 percent, the time of project lasts 130 days $(32+98)$ more than the preliminary time schedule of project and the project faces with delay. But if the corrective actions are executed, this time reduces to 32 days (Figure 6). Simulation and prediction of the project completion dates and final cost are revealed for three plans by the Latin Hyper Cub method in Figure 7 and Figure 8. The comparison of simulation results with the Latin Hyper Cub method for final expenditures of three plans shows that if project liability does not consider safety risks and do not perform corrective actions, the final cost of the project is $28875 \$(10623+18252)$ in comparison to the preliminary project schedule and it finally faces with cost overrun. By considering and performing corrective actions, this increase in cost will be limited to 10623 \$ (Figure 8). As the simulation result, probability of $41 \%$ is possible for finishing the project in deterministic duration depend on the preliminary schedule of the project. But after the recognition of safety risks, the possibility of project completion for the objective of project time reduces to less than 1 percent and if the corrective actions are executed, the probability of project completion for preliminary project schedule in definite duration is 14 percent. By chance of 80 percent, if the plan of responding to risk is implemented, it is optimistic to complete the project in 331 days (Fig. 6 \& Fig. 7). Correlation coefficient is a tool for determining the type and degree of a quantitative variable with a few other variables and is used to determine the correlation of the two variables. The sensitivity of the time and cost of a risk involves measuring the relationship between the occurrence of each of its effects on the time and cost of the project (Hulett, 2016). After completing the Latin hypercube simulation process, Pearson correlation coefficient is used for correlation analysis. In order to determine the effectiveness of the response to the safety risks, the sensitivity analysis for the safety risks integration program and activities are used prior to the corrective actions and after the corrective actions to determine the usefulness of the corrective actions with respect to priority Configuration of the fuzzy expert system. Fig. 9 shows that if corrective actions are carried out based on the prioritization of the fuzzy expert system, how much the impact of the risks on the schedule and cost of the project is on the initial effect before the implementation of safety measures can be reduced.

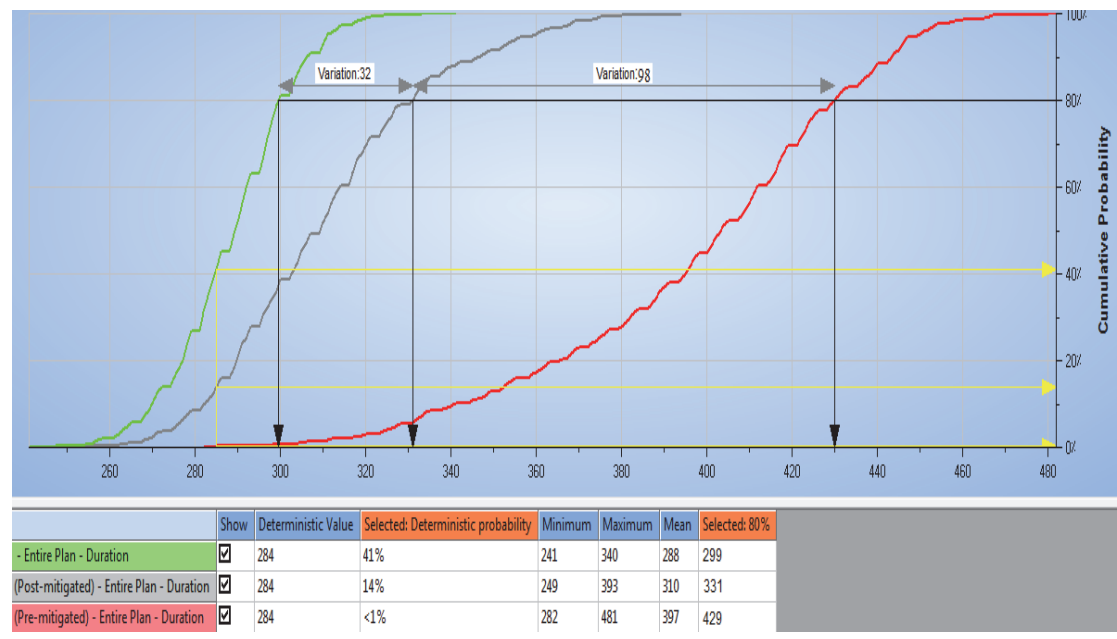

Fig. 6. Simulation of project duration for three plans 


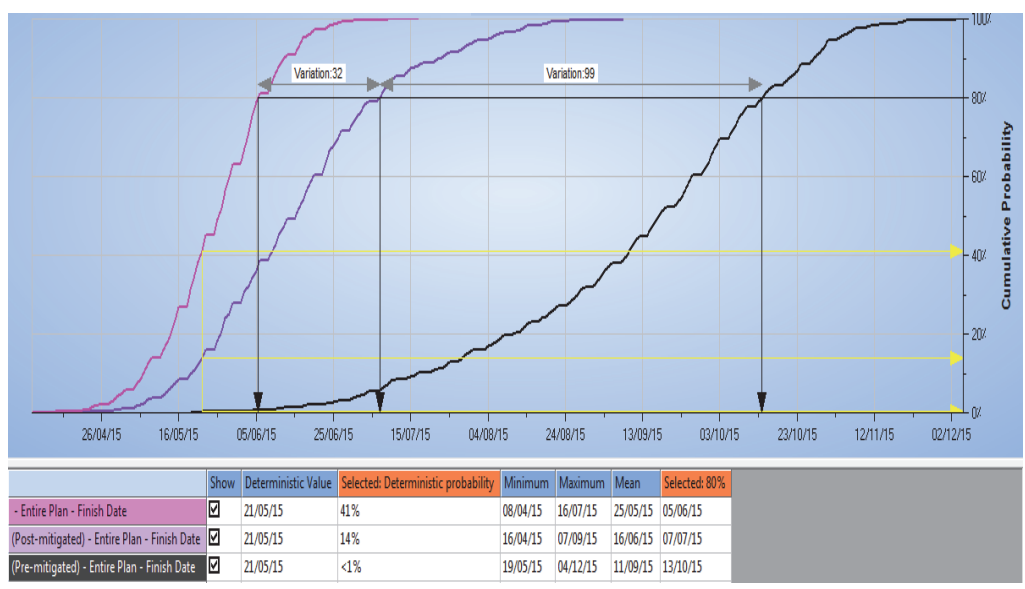

Fig. 7. Simulation of the project completion dates for three plans

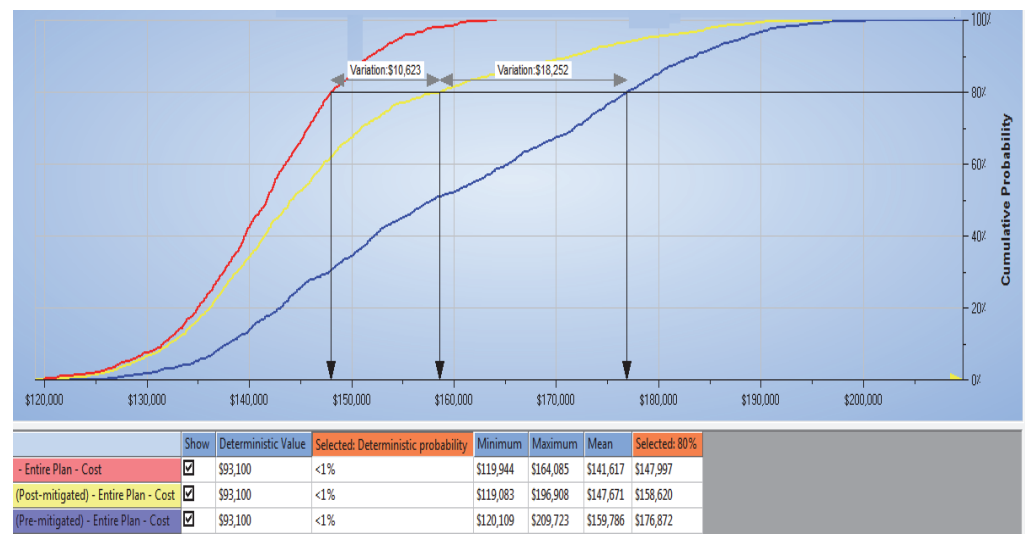

Fig. 8. Simulation of the final cost of the project for three plans
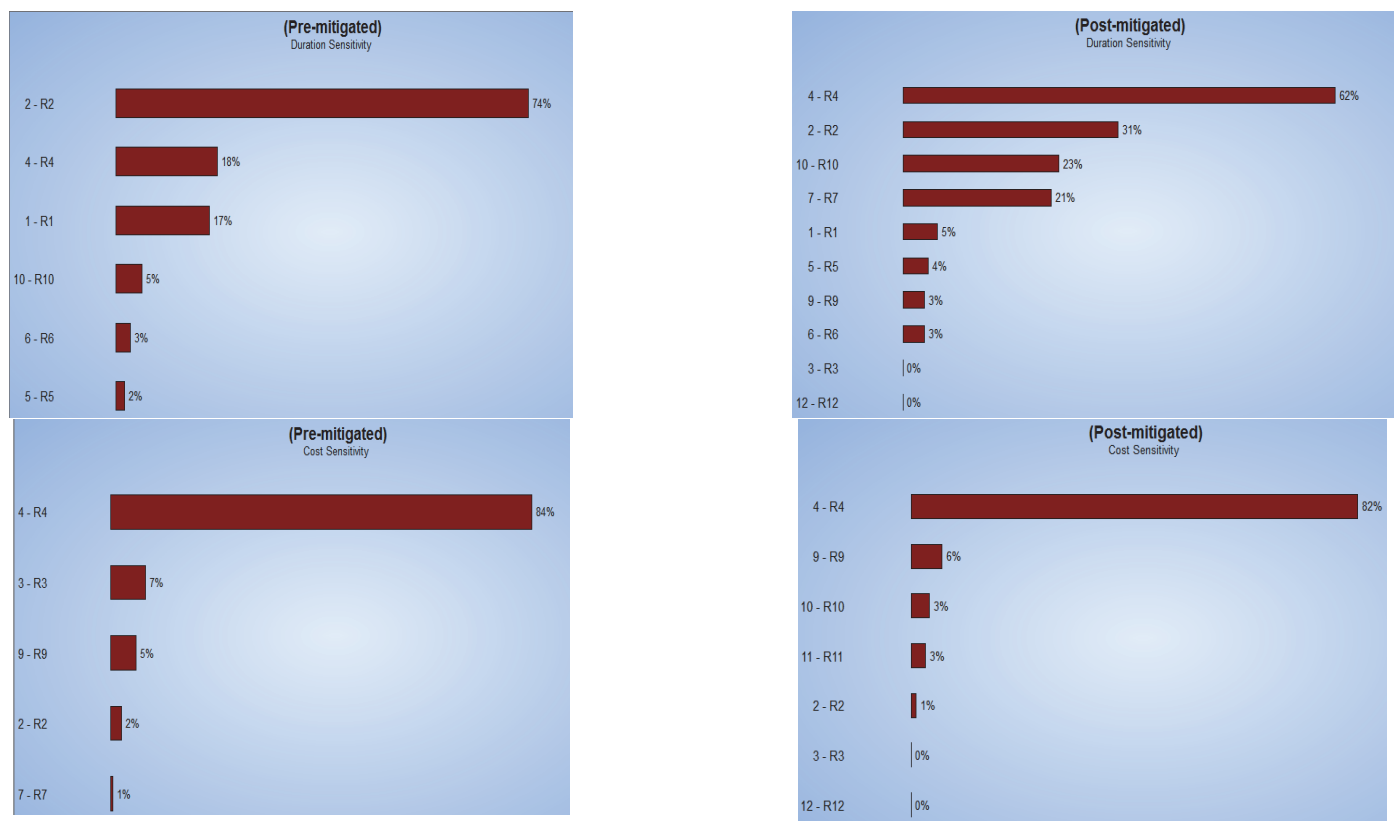

Fig. 9. Sensitive Analysis before and after corrective actions 


\section{Conclusion}

In this research, the results of the proposed hybrid model (Fuzzy Inference System\& Latin Hyper Cube simulation) were analyzed in a case study. Firstly, model inputs inclusive of time and cost schedule of project activities are gathered. After that, Latin Hyper Cube simulation was done on preliminary schedule. Then, level of definite project schedule was specified. After recognizing OHS risks and specifying the level of uncertainty of occurrence and risks effect by using designed Fuzzy inference system, identified safety risks were prioritized for responding. Then, strategies and corrective actions were selected. The integrated plan of risks and activities were provided before identifying the OHS risks, after the responding plan and performing corrective actions. Simulation was done on duration, end date, final cost, and net present value of costs by Latin hypercube method. For assessment and validation, outcomes of three plans (preliminary plan, integrated plan before responding and after corrective actions) were summarized to help project experts and managers not only concentrate on delays and extra cost but also have a better simulation of project goals, including time and final project cost. In this research, the proposed model was assessed just in a single case study. For future works and researches, it is possible to work on a model to mix and implement the proposed model of this article in enterprise project management (EPM).

\section{References}

Aminbakhsh, S., Gunduz, M., \& Sonmez, R. (2013). Safety risk assessment using analytic hierarchy process (AHP) during planning and budgeting of construction projects. Journal of safety research, 46, 99-105.

Aubert, B. A., \& Bernard, J.-G. (2004). Mesure intégrée du risque dans les organisations: PUM.

Badri, A., Gbodossou, A., \& Nadeau, S. (2012). Occupational health and safety risks: Towards the integration into project management. Safety Science, 50(2), 190-198.

Badri, A., Nadeau, S., \& Gbodossou, A. (2012). Proposal of a risk-factor-based analytical approach for integrating occupational health and safety into project risk evaluation. Accident Analysis \& Prevention, 48, 223-234.

Baradan, S., \& Usmen, M. A. (2006). Comparative injury and fatality risk analysis of building trades. Journal of Construction Engineering and Management, 132(5), 533-539.

Benjaoran, V., \& Bhokha, S. (2010). An integrated safety management with construction management using 4D CAD model. Safety Science, 48(3), 395-403.

Dement, J. M. (1999). Workers' compensation experience of North Carolina residential construction workers, 1986-1994. Applied Occupational and Environmental Hygiene, 14(2), 97-106.

Deshmukh, A., \& Romine, J. (1998). Assessing the risk of management fraud using red flags: a fuzzy number based spreadsheet approach. Journal of Accounting and Computers, 4(3), 5-15.

Gürcanli, G. E., \& Müngen, U. (2009). An occupational safety risk analysis method at construction sites using fuzzy sets. International Journal of Industrial Ergonomics, 39(2), 371-387.

Hagigi, M., \& Sivakumar, K. (2009). Managing diverse risks: An integrative framework. Journal of International Management, 15(3), 286-295.

Hallowell, M. R. (2008). A formal model for construction safety and health risk management: Oregon State University.

Hare, B., Cameron, I., \& Roy Duff, A. (2006). Exploring the integration of health and safety with preconstruction planning. Engineering, Construction and Architectural Management, 13(5), 438-450.

Harms-Ringdahl, L. (2003). Safety analysis: principles and practice in occupational safety: CRC Press.

Hulett, D. (2016). Integrated cost-schedule risk analysis: Routledge.

Iman, R. L., Helton, J. C., \& Campbell, J. E. (1981). An approach to sensitivity analysis of computer models: Part I-Introduction, input variable selection and preliminary variable assessment. Journal of Quality Technology, 13(3), 174-183.

INE, I. d. E. (2008). Statistical yearbook of Portugal 2007. 1 vols. Lisboa: Instituto Nacional de Estatística, IP.

Islam, M. S., Nepal, M. P., Skitmore, M., \& Attarzadeh, M. (2017). Current research trends and application areas of fuzzy and hybrid methods to the risk assessment of construction projects. Advanced Engineering Informatics, 33, 112-131.

Jannadi, O. A., \& Almishari, S. (2003). Risk assessment in construction. Journal of Construction Engineering and management, $129(5), 492-500$. 
Kautt, G., \& Wieland, F. (2001). Modeling the future: the full Monte, the Latin hypercube and other curiosities. Journal of Financial Planning, 14(12), 78-78.

Kendrick, T. (2015). Identifying and managing project risk: essential tools for failure-proofing your project: AMACOM Div American Mgmt Assn.

Lafuente, E., \& Abad, J. (2018). Analysis of the relationship between the adoption of the OHSAS 18001 and business performance in different organizational contexts. Safety Science, 103, 12-22.

Lee, S., Halpin, D. W., \& Chang, H. (2006). Quantifying effects of accidents by fuzzy-logic-and simulationbased analysis. Canadian Journal of Civil Engineering, 33(3), 219-226.

Leigh, P. J., \& Miller, T. R. (1997). Ranking occupations based upon the costs of job-related injuries and diseases. Journal of Occupational and Environmental medicine, 39(12), 1170-1182.

Lipscomb, H. J., Dement, J. M., \& Behlman, R. (2003). Direct costs and patterns of injuries among residential carpenters, 1995-2000. Journal of Occupational and Environmental medicine, 45(8), 875-880.

Lipscomb, H. J., Glazner, J. E., Bondy, J., Guarini, K., \& Lezotte, D. (2006). Injuries from slips and trips in construction. Applied ergonomics, 37(3), 267-274.

Liu, Z., \& Guo, C. (2009). Study on the risks management of construction supply chain. Paper presented at the Service Operations, Logistics and Informatics, 2009. SOLI'09. IEEE/INFORMS International Conference on.

McKay, M. D., Beckman, R. J., \& Conover, W. J. (1979). Comparison of three methods for selecting values of input variables in the analysis of output from a computer code. Technometrics, 21(2), 239-245.

Monarca, D., Cecchini, M., Colantoni, A., Gubiani, R., \& Vello, M. (2008). IS Project: a methodology of evaluation for integrated systems in agroindustrial sector. Innovation Technology to Empower Safety, Health and Welfare in Agriculture and Agro-food Systems. Ragusa, 15-17.

Pheng, L. S., \& Kwang, G. K. (2005). ISO 9001, ISO 14001 and OHSAS 18001 management systems: integration, costs and benefits for construction companies. Architectural Science Review, 48(2), 145-151.

Pinto, A., Nunes, I. L., \& Ribeiro, R. A. (2011). Occupational risk assessment in construction industry-Overview and reflection. Safety Science, 49(5), 616-624.

PMI. (2008). A guide to the project management body of knowledge.

Rozenfeld, O., Sacks, R., Rosenfeld, Y., \& Baum, H. (2010). Construction job safety analysis. Safety Science, 48(4), 491-498.

Siegel, P. H., De Korvin, A., \& Omer, K. (1995). Applications of fuzzy sets and the theory of evidence to accounting (Vol. 2): Jai Press.

Tong, R., Cheng, M., Zhang, L., Liu, M., Yang, X., Li, X., \& Yin, W. (2018). The construction dust-induced occupational health risk using Monte-Carlo simulation. Journal of Cleaner Production.

Van Dorp, J., \& Duffey, M. (1999). Statistical dependence in risk analysis for project networks using Monte Carlo methods. International Journal of Production Economics, 58(1), 17-29.

Waehrer, G. M., Dong, X. S., Miller, T., Men, Y., \& Haile, E. (2007). Occupational injury costs and alternative employment in construction trades. Journal of Occupational and Environmental medicine, 49(11), 12181227.

Wu, W., Yang, H., Chew, D. A., Yang, S.-h., Gibb, A. G., \& Li, Q. (2010). Towards an autonomous real-time tracking system of near-miss accidents on construction sites. Automation in Construction, 19(2), 134-141.

Zare Mehrjerdi, Y., \& Haqiqat, E. (2015). Developing a conceptual model based upon the Latin Hypercube Sampling for integrating OHS into project risk evaluation. International Journal of Industrial Engineering \& Production Research, 26(4), 229-241.

Zio, E. (2013). The Monte Carlo simulation method for system reliability and risk analysis (Vol. 39): Springer.

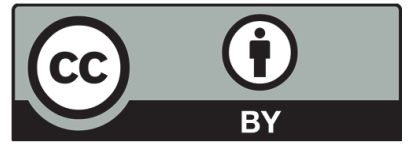

(C) 2019 by the authors; licensee Growing Science, Canada. This is an open access article distributed under the terms and conditions of the Creative Commons Attribution (CC-BY) license (http://creativecommons.org/licenses/by/4.0/). 